\title{
Seismic Risk Management practices in metalliferous mines
}

\author{
Y. Potvin' ${ }^{1}$, J. Wesseloo' ${ }^{1}$, G. Morkel ${ }^{1}$, S. Tierney ${ }^{1}$, \\ K. Woodward ${ }^{1}$, and D. Cuello ${ }^{2}$ \\ 1The University of Western Australia \\ ${ }^{2}$ Newcrest Mining Ltd
}

\begin{abstract}
The management of seismic risks in metalliferous mines operating in developed mining countries such as Australia, Canada, Chile and Sweden has been very successful during the last decade. The occurrence and magnitude of large seismic events in deep mines has continued to increase with mining reaching deeper horizons, yet, injuries and fatalities due to rockbursts remain very rare in these countries.
\end{abstract}

Although there are many common practices used to manage seismic risks in mines, there is no recognised process to do so. In 2017, Newcrest Mining Ltd, in collaboration with the Australian Centre for Geomechanics (ACG), undertook a benchmarking campaign to document the different seismic risk management practices currently implemented in mines which are considered leaders in this area. Data was gathered from 16 mines operating in five countries, experiencing different degrees of seismicity. Analysis of the data from the benchmarking study led to a better understanding of seismic risk management practices applied in the industry.

One of the important outcomes of this project was the development of a flowchart describing in detail a generic seismic risk management process. The process is broken into four different layers of activities: data collection, seismic response to mining, control measures, and seismic risk assessment.

Within each layer of activity, there are a number of components, and within each component, there are a number of practices, which have been benchmarked and are discussed in this paper.

In addition to providing a road map for managing seismicity in underground metalliferous mines, this work enables users to assess their own practices against standard and advanced practices in the management of seismic risks. A full description of the seismic risk management process is available to the mining industry at https://acg.uwa.edu.au/srmp.

\section{INTRODUCTION}

In seismically active underground mines, seismic risk is often classified as extreme because the most severe consequences may result in multiple fatalities and long periods of mine shut down, and in the worst case, permanent closure. The pro-active management of seismic risk is, therefore, paramount for mines operating in seismically active conditions. 
The literature on mine seismicity and the various techniques to manage seismic risks is abundant. Dedicated conferences have been held on Rockburst and Seismicity in Mines (RaSiM) since 1982. Some guidelines have been proposed for example, Durrheim et al (2007) focusing on standard and best practice in South African deep level tabular mines, and Essrich (2005), outlining suggested competencies for rock engineering practitioners in the same environment. Many of the practices applied worldwide are common to many operations, yet, there is no generally accepted process to manage seismic risks in hard rock mines.

Newcrest Mining Ltd, in collaboration with the ACG, has undertaken the task of defining a process that best describes seismic risk management, with the intent to better understand what best practice in managing seismic risks in mines would look like.

The project, which was initiated in July 2017, started with a comprehensive benchmarking exercise of seismically active mines. Data was gathered from a combination of mine visits and interviews. Sixteen mines operating in five countries, experiencing different degrees of seismicity, contributed data. To supplement this data, a separate survey was distributed to mine operations using the $\mathrm{mXrap}$ software Harris and Wesseloo (2015), asking how frequently, various seismic analysis techniques were used onsite. There were 30 responses to the seismic analysis survey from a variety of operations around the world.

The results of this project are being made available to the mining industry at https://acg.uwa.edu.au/ srmp, Potvin et al (2019). This project provides a cross-section of the seismic risk management practices used in underground hard rock mines around the world. It should be noted that it provides an overview of what is being done, and should not be seen as a guideline of what should be done. It does, however, provide an important benchmark against which every site can evaluate its own risk management practices.

As the industry further develop methods to deal with mining induced seismic risk, this process summary will need to be updated.

\section{SEISMIC RISK MANAGEMENT PROCESS (SRM process)}

The proposed SRM Process is best shown as a flowchart (See Figure 1). The process is broken into four different layers:

- Data collection,

- Seismic response to mining,

- Control measures,

- Seismic risk assessment.

Within each layer, there are a number of components. For example, the data collection layer comprises four components encompassing different types and sources of data necessary for seismic risk management. In total, the four layers are subdivided into 12 components (See Figure 1). Each component is further divided into a number of practices, leading to a total of 42 practices (From 1.1 to 12.2, Figure 1). The large number of practices (42) listed in the flowchart emphasises the complexity of the seismic risk management process at mine sites. 


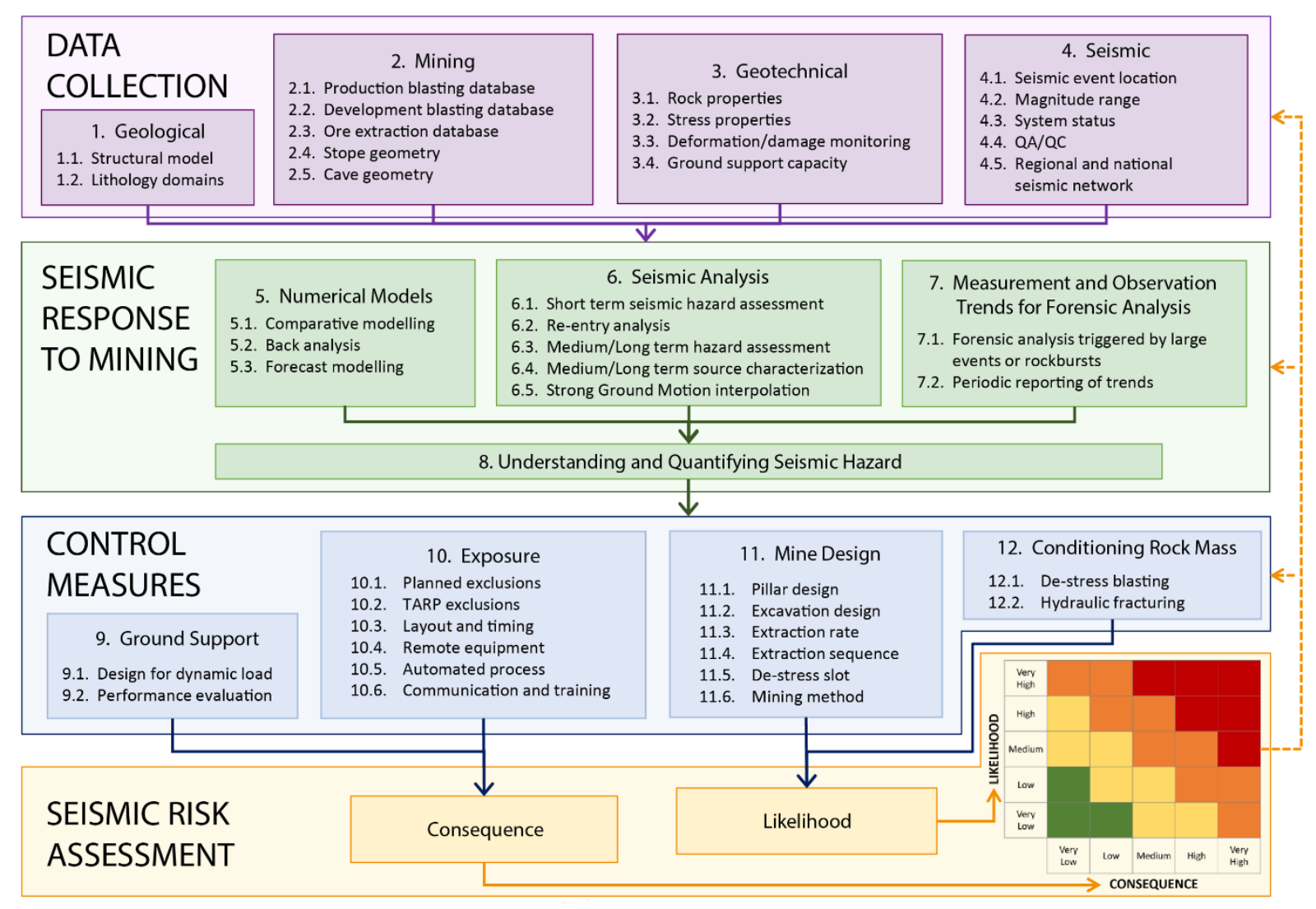

Figure 1. Seismic risk management process flowchart

\section{BEST PRACTICE IN MANAGING SEISMIC RISK IN MINES}

The original scope of the project was to define best practice in managing seismic risk in mines. It was realised early on that best practice is difficult to define, and in fact, the notion of best practice, when applied to seismic risk management, is not a universal concept. Best practice at a mine site is necessarily a function of the intensity and complexity of the seismic problem at that site. As such, it is not always necessary nor best practice for mines experiencing low seismic hazard to implement, for example, extensive and advanced seismological analyses. Hence low, medium and severe seismic hazard will call for different best practices.

To circumvent this issue, we have decided to refer to standard and advanced practices. Standard practices indicate approaches commonly used at most mine sites. Advanced practices involve techniques that are uncommon due to:

- $\quad$ requiring personnel with a high skill base; and/or

- being labour/computing/time intensive.

It is also important to realize that not all practices described in the SRM process are relevant to every operation and the applicability or effectiveness depends on the mining method, the geological and/or 
geotechnical conditions at the mine. In fact, for mines where the seismic hazard is not high, the SRM process can be simplified significantly.

Therefore, the goal of the project shifted from creating a process that defines best practice to a tool that can be used to provide a road map for managing seismicity in underground metalliferous mines, notwithstanding the level of seismicity experienced by the mine. The SRM process also enables users to assess their own practices against standard and advanced practices in the management of seismic risks. It provides an opportunity to identify where potential improvements can be made, and whether the cost of such improvement can be justified from the potential benefits derived from up-grading to advance practices.

Each SRM process component has a description of the practices used in the mining industry along with a summary table that briefly outlines the standard and advanced practices. An example of the summary table for numerical modelling is shown in Figure 2. The seismic risk management process and detailed description of practices is available to the mining industry at acg.uwa.edu.au/srmp.

\begin{tabular}{|c|c|c|}
\hline & Standard Practices & Advanced Properties \\
\hline 5.1 Comparative Modelling & $\begin{array}{l}\text { - Compare shear stress on } \\
\text { major structures for } \\
\text { different extraction } \\
\text { sequences using 3D } \\
\text { elastic model } \\
\text { - Assess stress/ energy/ } \\
\text { displacement criteria for } \\
\text { different excavation } \\
\text { arrangements }\end{array}$ & $\begin{array}{l}\text { - Compare anticipated seismic } \\
\text { responses for different } \\
\text { sequences } \\
\text { - Assess the effect of different } \\
\text { loading sequences on the } \\
\text { rock mass and exposure of } \\
\text { work areas based on } \\
\text { variations in mine design }\end{array}$ \\
\hline ck Analysis & $\begin{array}{l}\text { - Review stress conditions } \\
\text { leading up to previous } \\
\text { large events } \\
\text { - Consider whether } \\
\text { observed rock mass } \\
\text { behaviour matches } \\
\text { expectations, review } \\
\text { input parameters if } \\
\text { necessary }\end{array}$ & $\begin{array}{l}\text { Back analyse fault strength } \\
\text { properties based on } \\
\text { recorded large events that } \\
\text { have caused damage and } \\
\text { also on the large events that } \\
\text { have not caused damage } \\
\text { - Forensic sub-models to } \\
\text { identify rock mass failure } \\
\text { mechanisms }\end{array}$ \\
\hline 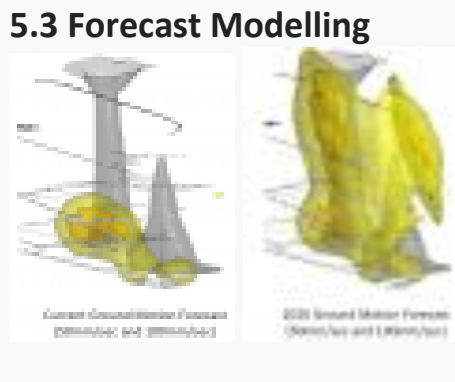 & $\begin{array}{l}\text { - Use established } \\
\text { correlations to assess } \\
\text { potential conditions as } \\
\text { mining progresses } \\
\text { - Identify trigger levels in } \\
\text { model results that } \\
\text { correlate to observed } \\
\text { behaviour }\end{array}$ & $\begin{array}{l}\text { - Assess stress, damage and } \\
\text { energy release of future } \\
\text { mining sequence from } \\
\text { elasto-plastic model } \\
\text { - Assess future seismic } \\
\text { response, frequency and } \\
\text { event size distribution using } \\
\text { Salamon-Linkov modelling }\end{array}$ \\
\hline
\end{tabular}

Figure 2. Summary table for standard and advanced numerical modelling practices 


\section{DATA COLLECTION}

It is important to note that the management of mining induced seismic risk, requires several different data types from different data sources and not only seismic data. There are four components of the data collection layer: Geology, Mining, Geotechnical and Seismic. With the exception of seismic data, all other data are generally available in some form at most mine sites. Because these existing data were collected with a purpose other than seismic management, there are often a number of challenges that need to be addressed to make good use of such data.

For example, structural models are often developed at the exploration and early stages of mine development with the aim of understanding the orebody reserves and resources. The structural models are not always up-dated. When structural geologists work on a mine site, their work is generally dedicated to new exploration targets, so the original structural model, focussing on the orebody being mined, is often neglected and out of date. The extensive use of shotcrete in many mines is preventing visual access to rock mass exposure and may also hamper the continuous refinement and validation of structural models in operating mines. The structural models are developed and maintained from a mineralisation perspective and the geotechnical characteristics (e.g. structure, width, infill characteristics) are often neglected.

Mining data may be deficient and lacking in some details which are important for seismic analyses but of little interest to production personnel. An example of this is the recording of the coordinates and exact times of initiation of every development blast. This data, which is critical to investigate the seismic response to blasting and the development of statistically-based exclusion time after blasts, is often incomplete because it is unimportant for production purpose.

In addition to blasting information being imperfectly recorded, production bogging data is rarely stored in a useful manner for analysis. The rate of production bogging is often used as a potential explanation for seismic activity but the data is not recorded to properly analyse the connection between seismicity and rates of extraction.

The survey also found that the mining geometry is often not archived. The current development and void is nearly always available but the records of the precise geometry in previous months and years is not so commonly retained. Mine geometry has a key influence on the occurrence of seismicity and many investigations and back analysis rely on this input data to make useful conclusions.

It is also often a challenge to have a common platform to enable interaction and comparison between the different databases. The advanced practice in data collection will have a wide range of data, properly organised in databases with good visualisation, facilitating easy access and regular uses in multiple analyses across all databases.

Good quality seismic data is, of course, paramount, for seismic risk management and QA/QC (Quality Assurance/Quality Check) of seismic data is very important. This aspect is often overlooked, as it is not always apparent what impact data quality artefacts can have on the results of analysis techniques. Recently, Morkel and Wesseloo (2017), showed that 19 of the 20 sites they investigated had large changes in source parameter values due to changes in seismic system settings. These changes were not due to natural changes in the rockmass, but rather introduced by poor QA/QC practices. 


\section{SEISMIC RESPONSE TO MINING}

Seismic monitoring systems in mines are used worldwide and are often seen as the main foundation in managing seismicity. Numerous simple seismological analyses are routinely used in most mines, whilst more sophisticated source parameter studies are less common.

The seismic response to mining (Green layer Figure 1) is where the seismic sources in the mine are identified, understood and the seismic hazard is quantified, before control measures are applied to reduce the seismic risk to a tolerable level.

The main tools to investigate the seismic response to mining are:

- $\quad$ Numerical models (elastic, elasto-plastic);

- $\quad$ seismological models (source location, source parameters, source mechanisms, tomography); and statistical and trend analyses of seismic data, and

- regular underground observations and case studies of the historical seismic response to mining.

Both numerical modelling and seismological modelling are in the domain of highly specialised fields. Therefore, the mining industry is very reliant on outside specialist consultants to complete these modelling tasks. On the other hand, the daily observations and the investigation of case studies is largely completed by site-based personnel. Hence, we have three sources of information generally produced by three separate groups that needs to be integrated and turned into knowledge. Two of the sources are the results of models and the third source is observations. Due to the indirect nature of seismic monitoring, consisting of several layers of processing and interpretation subject to theoretical models and assumptions, it is important to recognise that the seismic monitoring process results in models rather than data.

This situation lends itself to a number of traps commonly observed in seismic risk management practices at mine sites. Often, the generation of the knowledge, i.e. the understanding and forecasting of seismic hazard, is dominated by one of the three sources of information with insufficient input from the other two. In many instances, the interpretation of the seismic hazard is either dominated by numerical models or by seismological models. It is also often the case that the observations and learnings from case studies are of relatively poor standard due to the lack of resources at mine sites. The industry investment in generating knowledge from the two models are generally very significant, whilst the investment in learning from observations is too often deficient.

As a result, the part of the process dedicated to understanding of the seismic response to mining (Green layer) is highly variable from mine to mine, and as mentioned before, is often dominated by the interpretation of one of the two types of models (Rock mass stress/displacement-based models or seismological models). The link between the cause (i.e. mining activity) and effect (i.e. seismic response) is generally not investigated in enough detail.

Ideally, the two types of models should be compared to each other and more importantly, extensively related to reality (observations and case studies) to achieve some level of understanding of the seismic sources and how these sources are responding to mining. Only then, can the forecasting of seismic hazard be done with some level of confidence. This can only happen at mines that have access to a person who has sufficient understanding of numerical modelling, seismological analysis techniques and who is also intimately familiar with site observations. Such a person must have dedicated time to study the models and produce this essential knowledge.

Operations with advanced seismic risk management practices tend to emphasise investigations done periodically and as a response to a change in seismic behaviour. When a significant incident such as a large event occurs, a forensic analysis is performed using all of the available data and analysis 
techniques to investigate the root causes of the event and whether the current control measures are sufficient in light of the recent developments.

\section{CONTROL MEASURES}

The blue layer of activities in the flowchart describes the control measures (See Figure 1) that can be implemented to mitigate the seismic hazard as defined in the previous step of the process. Ground support and exposure controls aim at mitigating the consequences of seismic activity. These techniques are employed in all seismically-active mines.

\section{Ground support}

Ground support under dynamic loading is a specialized field required to mitigate the potential consequences of seismic events in mines. New ground support products are constantly being developed and trialed at mine sites.

Ground support is often perceived as the main tool to mitigate the consequence of seismicity. Based on a forecast of the largest event in each area of the mines, ground support systems are designed and implemented to contain such events. Despite a large effort by the industry to improve knowledge of dynamic ground support behaviour, the theoretical basis and design methodologies for dynamic ground support remain deficient.

It is noted that advanced practice should involve the assessment and rehabilitation of ground support if required, after large events. This includes cases where visible damage occurred without any fall of ground. It is an increasingly common practice for mines to use displacement data from before and after laser scan measurements. These measurements are used to estimate the consumed and residual capacity of the ground support and the need for proactive rehabilitation after significant seismic events.

QA/QC is an important parameter in the dynamic capacity of ground support and advanced practice includes a comprehensive and efficient ground support QA/QC system to ensure that the installed capacity remain sufficient for expected demand throughout its functional life. Also, an important factor potentially affecting the capacity of ground support is corrosion. However, most mines do not have tools to quantify the effect of corrosion on ground support capacity.

\section{Personnel exposure}

Seismic hazard is elevated following abrupt stress changes, for example due to blasting, which result in periods of increased seismicity. This increased seismicity often clusters in space with the activity rate decaying over time (Seismic response). These responses can sometimes be relatively consistent but more often they are highly variable in nature and their influencing factors are not well understood. Seismic responses routinely occur following blasting and large seismic events. The vast majority of seismically-active mines aim to limit personnel exposure during periods of heightened seismicity to reduce risk using exclusion and re-entry protocols.

Exclusions can be planned in the case of blasting. The planned exclusion generally has two main parameters; an exclusion time and an exclusion space. As a standard practice, the exclusion time in many mines is set as a blanket rule, based on experience. For example, development mining blast may have a 3-hour exclusion time that extends to a radius of 30 metres from the blast location. More advanced practices determine the exclusion based on statistical analyses of the historical seismic response. The exclusion time and space can be variable in different regions of the mine and the reentry can be assessed in quasi-real time. 
Production blasting exclusions are often treated differently to development firings, as they are expected to trigger more significant stress change and seismic responses than development firings. This may not always be the case, for example, when production firing takes place in stress shadows. Development blasting sometimes results in anomalously high seismic responses.

Exclusion can also be triggered by anomalous responses such as intense seismic activity and/or large events. Other practices to reduce exposure may include changing mine layouts to minimise accesses in high hazard areas, increasing used of remote or fully automated equipment. Better education, training and education to the workforce can also reduce exposure by raising their awareness of the signs of elevated seismic hazard.

\section{Mine design}

Changes in mine design aim to reduce the seismic risk by either reducing the seismic hazard or the consequence. These controls are generally more difficult to apply routinely but, in some cases, can be very efficient in reducing seismic risk.

Different aspects of mine design may be considered to control seismic risk. Mine design may directly influence seismic hazard, for example, by designing for favourable stress conditions; or can influence seismic risk indirectly by creating more flexibility for effective exposure control (i.e., reducing the consequence). Different aspect of a mine design may compete and result in trade-offs; for example, more flexibility in the mine plan may require more pillars which will result in more seismicity. The overall reduction in seismic risk should be the aim of mine design seismic control measures rather than local or short-term gain.

Safety is paramount in mine operations. It has been observed that mines experiencing very severe seismic response, at some points, will become seismically controlled mines. This means that most mine design decisions will become controlled by the anticipated seismic response. This means that the traditional drivers of mine design, such as. costs, production rates, grade, recovery, will become secondary to the layout designed to minimise seismic risks.

\section{Conditioning the rock mass}

It is possible to reduce seismic hazard by modifying the rock mass properties using pre-conditioning techniques such as blasting or hydraulic fracturing to change its seismic response to mining-induced stress changes. This can be done at the scale of a drive (de-stress blasting), or at the very large scale of a block or panel cave mine using hydraulic fracturing or confined blasting. Large scale hydraulic fracturing has the added advantage in caving mines to improve fragmentation and as such it is increasingly used with this mining methods. However, hydraulic fracturing is yet to be applied as a method to reduce seismic hazard in mines other than block/panel caving, although trials are undertaken at LKAB at the time of writing this paper.

\section{SEISMIC RISK ASSESSMENT}

The yellow area in the flowchart represents the risk assessment (See Figure 1). The management of seismic risk is generally performed within a broader risk management framework.

Some level of risk assessment appears to be common practice on mines and is generally prescribed by national or state legislative bodies. The level of risk assessment varies from informal to formal and qualitative to quantitative.

Typically, experience-based subjective evaluation of the consequences and probabilities associated with seismic hazards are performed, and its acceptance within the corporate risk matrix is evaluated. Formal risk assessment techniques include the use of fault event trees with subjectively assigned component likelihoods. Informal risk assessment should be limited to tactical decisions of limited consequence events and should not form the basis for strategic decisions. 
Different levels of improvement are possible on the informal subjective risk assessment discussed the previous paragraph.

\section{The individual formal subjective risk assessment}

The geotechnical engineer performs a risk assessment employing formal risk assessment techniques like fault event trees and assign subjective probabilities to the components of such trees. This risk assessment is documented in a memorandum and the subjective probabilities listed. The documentation enables auditing and expert evaluation of the risk assessments. After the initial development of the fault event trees for a specific scenario, this process is not onerous.

\section{Formal subjective risk assessment employing expert opinion}

The employment of expert opinion to derive subjective probabilities in a formal risk assessment is well documented in geotechnical engineering context, for example, Vick (2002), and Baecher and Christian (2003). A panel of experts are selected and a facilitator manages the risk assessment according to well established processes. The risk assessment process is documented.

\section{Quantitative risk assessment}

Probabilistic calculations are performed to evaluate the probabilities required in the formal risk assessment employing fault- and event trees. The calculation process and the risk assessment process is documented. This level of seismic risk assessment has not been observed in mines by the authors.

\section{SUMMARY}

Seismic risk management in mines is a complex process with best practice being governed by site specific conditions. A flowchart describing a generic seismic risk management process has been proposed based on an extensive benchmarking exercise. The process comprises four layers of activities:

- Data collection

- $\quad$ Seismic response to mining,

- Control measures,

- $\quad$ Seismic risk assessment.

Each layer of activities is briefly discussed in this paper. The reader is referred to https://www.acg.uwa.edu.au/srmp, Potvin et al. for more details on the numerous standard and advanced seismic risk management practices identified during benchmarking.

The SRM Process enables users to assess their own practices against standard and advanced practices that can be applied for the management of seismic risks and provides a valuable framework for the development and evaluation of site-specific risk management plans.

\section{REFERENCES}

Baecher, G. B. \& Christian, J. T. (2003). Reliability and statistics in geotechnical engineering, Chichester, England; Hoboken, NJ, Wiley.

Durrheim, R. J., Cichowicz, A., Ebrahim-Trollope, R., Essrich, F., Goldbach, O., Linzer, L. M., Spottiswoode, S. M. \& Stankiewicz, T. 2007. Guidelines, Standards and Best Practice for Seismic Hazard Assessment and Rockburst Risk Management in South African Mines. In: Potvin, Y. (ed.) Proceedings of the Fourth International Seminar on Deep and High Stress Mining. Perth: Australian Centre for Geomechanics. 
Essrich, F. 2005. Mine Seismology for Rock Engineers - An Outline of Required Competencies. In: Potvin, Y. \& Hudyma, M. (eds.) Proceedings of the Sixth International Symposium on Rockburst and Seismicity in Mines Proceedings. Perth: Australian Centre for Geomechanics.

Harris, P. \& Wesseloo, J. 2015. mXrap v5. http://www.mXrap.com: Perth, Western Australia: The Australian Centre for Geomechanics, University of Western Australia., I. G. \& Wesseloo, J. 2017a. The effect of sensor frequency range on the estimation of the current hazard state. In: Submitted (ed.) 9th International Symposium on Rockbursts and Seismicity in Mines. Santiago, Chile.

Morkel, I. G. \& Wesseloo, J. 2017. A technique to determine systematic shifts in microseismic databases. In: Wesseloo, J. (ed.) Proceedings of the Eighth International Conference on Deep and High Stress Mining. Perth: Australian Centre for Geomechanics.

Potvin, Y., Wesseloo, J., Woodward, K., Morkel, I. G. \& Tierney, S. R. Seismic Risk Management Practices in Underground Mines [Online]. Available: https://www.acg.uwa.edu.au/srmp [Accessed 2019].

Vick, S. 2002. Degrees of Belief: Subjective Probability and Engineering Judgement, New York, American Society of Civil Engineers.

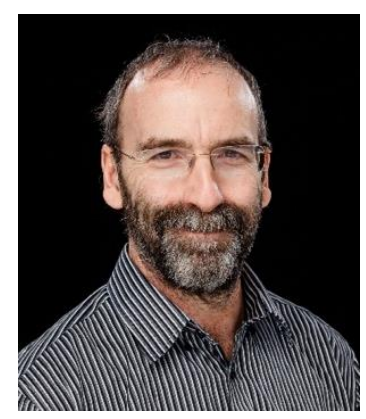

\section{Yves Potvin}

Director

Yves joined the Australian Centre for Geomechanics at the University of Western Australia in 1998 and was appointed Centre Director in 2000. Professor Potvin has published more than 100 articles and is the editor/co-editor of 16 conference proceedings/books. He has over 35 years experience in rock mechanics and mine design and has previously held managerial positions at Mount Isa Mines, the Noranda Technology Centre and worked as a mining engineer at Noranda Mines, Gaspe Division. 